\title{
Spectral characteristics of chest wall breath sounds in normal subjects
}

\author{
Noam Gavriely, Moshe Nissan, Ami-Hai E Rubin, David W Cugell
}

\section{Department of Physiology and Biophysics, Bruce Rappaport Faculty of Medicine, The Rappaport Family Institute for Research in the Medical Sciences and the Institute for Work Safety and Human Engineering, Technion, Israel Institute of Technology, Haifa, Israe N Gavriely M Nissan}

Pulmonary Division Rambam Medical Center, Haifa, Israel A-H E Rubin

Pulmonary Section and Anesthesia Department, Northwestern University Medical School and Northwestern Memorial Hospital, Chicago, USA N Gavriely D W Cugell

Reprint requests to: Dr N Gavriely, Pulmonary Physiology Unit, Faculty of Medicine, Technion IIT, P O Box 9697 , Haifa 31096, Israel.

Received 6 December 1994 Returned to authors 9 March 1995 Revised version received 26 May 1995 Accepted for publication 22 August 1995

\begin{abstract}
Background - This study was carried out to establish a reliable bank of information on the spectral characteristics of chest wall breath sounds from healthy men and women, both non-smokers and smokers. Methods - Chest wall breath sounds from 272 men and 81 women were measured using contact acoustic sensors, amplifiers, and fast Fourier transform (FFT) based spectral analysis software. Inspiratory and expiratory sounds were picked up at three standard locations on the chest wall during breathing at flows of 1-2 1/s and analysed breath by breath in real time.
\end{abstract}

Results - The amplitude spectrum of normal chest wall breath sounds has two linear parts in the log-log plane - low and high frequency segments - that are best characterised by their corresponding regression lines. Four parameters are needed and are sufficient for complete quantitative representation of each of the spectra: the slopes of the two regression lines plus the amplitude and frequency coordinates of their intersection. The range of slopes of the high frequency lines was $-12 \cdot 7$ to $-15 \cdot 2$ dB/oct during inspiration and -13.4 to $-20 \cdot 3 \mathrm{~dB} /$ oct during expiration. The frequency at which this line crossed the zero dB level - that is, the amplitude resolution threshold of the system - was designated as the maximal frequency (Fmax) which varied from 736 to $999 \mathrm{~Hz}$ during inspiration and from 426 to $796 \mathrm{~Hz}$ during expiration with higher values in women than in men. The mean (SD) regression coefficient of the high frequency line was $0.89(0 \cdot 05)$.

Conclusions - These data define the boundaries of normal chest wall breath sounds and may be used as reference for comparison with abnormal sounds.

(Thorax 1995;50:1292-1300)

Keywords: phonopneumography, lung sounds, normal standards, pulmonary acoustics, smokers, sex.

The diagnostic value of any clinical test or examination depends upon its ability to distinguish clearly, accurately, and in a repetitive manner between the normal and abnormal. Differentiation between various types of abnormalities is an additional important advantage. Phonopneumography is a procedure for the detection and analysis of respiratory sound utilising computerised spectral analysis of sounds picked up at specified sites on the chest wall and the trachea. ${ }^{1}$ It has recently been reported to improve the sensitivity of pulmonary health screening when combined with spirometric pulmonary function tests. ${ }^{2}$ Results of measurements in a substantial number of normal subjects are presented here.

Traditional auscultation with a stethoscope does not meet the requirements for a diagnostic test due, primarily, to limitations of the human auditory system. The ears are sensitive to deterministic sounds in the time or in the frequency domains, but are substantially less accurate in identifying, analysing, and classifying noise - that is, sounds that have a wide frequency band and/or poorly defined timing. Another reason for human deficiency in the auscultatory analysis of breath sounds is their low signal-to-noise ratio. Thoracic lung sounds have relatively low amplitude compared with background noise, heart sounds, and muscle sounds. Because of the subjectivity, lack of a permanent record, and the qualitative nature of breath sounds, many physicians no longer rely on auscultation as a diagnostic tool..$^{3-5}$

In a previous study ${ }^{1}$ the spectral characteristics of chest wall and tracheal breath sounds were measured in 10 normal young adults. The spectral pattern of normal chest wall breath sounds was found to have an exponential decay of sound amplitude with increasing frequency. Log-log presentation of the sound spectra showed a negative linear slope of approximately -12 to $-16 \mathrm{~dB} /$ oct with excellent goodness of linear fit for both inspiratory and expiratory sounds at all of the chest wall pick-up locations.

The present study extends the scope of previous phonopneumography measurements in a number of significant aspects: the population sample size has been increased leading to improved statistical significance; the ages of the subject are now more representative of the general adult population; the effects of sex and long term smoking on chest wall sounds have been evaluated; a more detailed and accurate description of the normal chest wall spectral pattern has been identified, particularly in the low frequency range; and technological advances have been incorporated into the methodology which now permits breath by breath real time computation of the average spectra and immediate assessment of the results. These improvements have allowed accurate characterisation of the normal chest wall breath sounds, documentation of differences between respiratory phases, pick-up locations, sex, and between smoking and non-smoking individuals, that have not been previously quantified. 


\section{Methods}

SUBJECTS

Four hundred and ninety three actively employed subjects were examined. They worked in two fertiliser factories $(n=157)$, a power plant $(n=81)$, three police units $(n=68)$, a local municipality $(n=99)$, a medical school $(n=67)$, and a medical centre $(n=21)$. Their occupational exposure to pollutants was no higher than for the average working population and did not exceed allowable standards. All of the subjects underwent standard spirometric pulmonary function tests, completed a pulmonary health questionnaire, ${ }^{6}$ and had their breath sounds recorded and analysed. Three hundred and fifty three subjects were deemed normal on the basis of all three procedures. In particular, they had normal spirometric values based on a scoring algorithm we have described earlier ${ }^{2}$ (Appendix), they did not answer affirmatively any of the questions related to previous or chronic respiratory ailments nor did they have any current respiratory symptoms, and their breath sounds were normal both by auscultation and by subsequent offline review of their recorded breath sounds (see below). Our observations on the sensitivity of this method in screening for lung diseases have been described elsewhere. ${ }^{27-9}$

This study was approved by the Technion's Institutional Human Use Review Board.

\section{LOCATION}

All tests were conducted at the subjects' work places. The equipment was placed in a relatively quiet but not noise-proof room. Ambient noises were occasionally disturbing and consequently some breath sound data had to be discarded (see Results).

\section{EXPERIMENTAL SYSTEM}

This study is based upon principles of the system previously described, ${ }^{126-9}$ but their application has been considerably enhanced by the use of advanced electronics and computers. A block diagram and a schematic flow chart of the system are shown in fig 1 . The subject breathed through a flow meter (Fleisch pneumotachograph no. 3, Gould Inc, Cleveland, Ohio, USA) connected to a differential pressure transducer (MP45, Validyne, Northridge, California, USA, $\pm 2 \mathrm{~cm} \mathrm{H}_{2} \mathrm{O}$ membrane). The flow signal was presented to the subject on an analog meter marked for inspiratory and expiratory flow rates at $1 \mathrm{l} / \mathrm{s}$. The flow signal was also digitised into the computer through a multichannel analog-to-digital (A/D) converter (MacADIOS II, 12 bit, \pm 10 volt A/D, GW Instruments, Somerville, Massachusetts, USA). Lung sounds were picked up simultaneously by three identical piezoelectric sensors (Alpha Omega, Phonopneumography Breath Sound Sensor Mark I, Nazareth, Israel) (fig 2A) placed on the chest wall (see test procedure below). The sensors were made of brass, weighed $85 \mathrm{~g}$, were $1.2 \mathrm{~cm}$ high, $3.8 \mathrm{~cm}$ in diameter, and had a thin stainless steel membrane $(2.8 \mathrm{~cm}$ in diameter $)$ on the side that was in contact with the patient. A piezoelectric crystal was glued to the stainless steel membrane, producing an electric signal proportional to membrane deformation. These sensors have a flat $\pm 3 \mathrm{~dB}$ frequency response from $62.5 \mathrm{~Hz}$ to $1500 \mathrm{~Hz}$ and resonances at 2500 and $5000 \mathrm{~Hz}$ (fig 2B). The sensors were attached to the chest surface using circumferential elastic straps that were adjusted to give firm contact between the sensor and the skin without restricting chest motion or causing discomfort. Radial forces of 100-180 g were thus generated. The gains and spectral output of the sensors used in this study were tested and found to be identical to each other and independent of attachment force provided complete contact between the sensor's surface and the chest was achieved (radial force of $>85 \mathrm{~g}$ ). The resulting breath sound signals were processed through three identical amplification and filtration channels (Alpha Omega, Phonopneumography Amplifier, Nazareth, Israel). The signals were amplified 10000 fold and passed through 18 $\mathrm{dB} /$ oct bandpass filters $(75-2000 \mathrm{~Hz})$. A magnetic tape recorder (AD-F360, Aiwa Co, Japan) was used in parallel with the computer as backup and for subsequent auditory reference and analysis.

\section{TEST PROCEDURE}

The spirometric pulmonary function tests were administered first, followed by the questionnaire. The three phonopneumography sensors were then attached at the right anterior chest in the mid clavicular line in the second intercostal space (CR), and at the right and left bases of the lung posteriorly in the eighth to tenth intercostal spaces in the mid scapular line ( $B R$ and $B L$, respectively). The acoustic measurements were conducted in the following order: (a) expiratory sounds; (b) inspiratory sounds; and (c) background sounds during breath holding.

The subject breathed through the flow transducer. Sound sampling was triggered when the flow reached a threshold of $1 \mathrm{l} / \mathrm{s}$ either in expiration or inspiration. Measurement of background noises was initiated by manual triggering that was activated by the operator while the subject held his/her breath. The duration of each sound segment was $0.512 \mathrm{~s}$ and contained 2048 points for each of the three sound channels and for the flow channel. The sampling rate was 4000 samples/s per channel. Following each sampling the computer calculated the magnitude of the amplitude spectrum using a fast Fourier transform (FFT) algorithm and averaged it with the spectra of the previous sound segments. The averaged spectra from each sensor were displayed online in a semi-logarithmic scale - that is, log magnitude versus frequency - providing visual online evaluation of the technical aspects of the test and its results. Six to eight seconds were needed to complete the processing and to display the data from each sampling period. Immediately thereafter the sounds from the next breath whose flow was above the threshold were sampled. With each additional sound seg- 


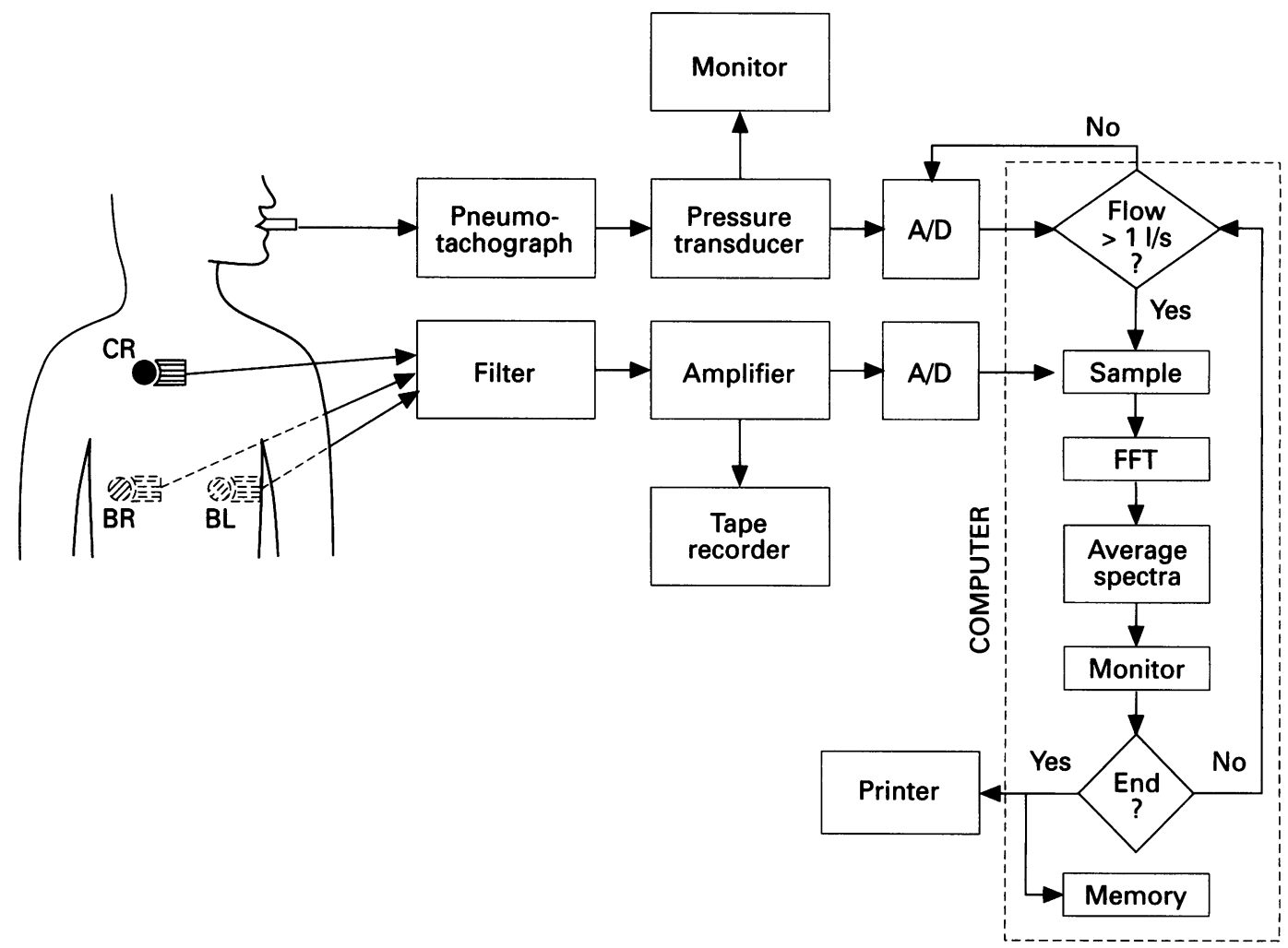

Figure 1 Schematic block diagram and flow chart of the phonopneumograph system. $C R, B R$, and BL are the pick-up locations on the right anterior chest, and the right and left posterior bases.

ment the displayed spectra converged while the noise around the spectral curve diminished at a rate proportional to the square root of the number of averaged segments, reaching a quasi steady state within $6-15$ breaths. The operator stopped the procedure once a stable pattern was observed on the computer screen. A convergence parameter - the variance of the $100-200 \mathrm{~Hz}$ spectral values normalised to the mean value of the spectrum within this range expressed as a percentage - was also calculated and displayed online as an aid to the decision making by the operator. The averaged spectra were stored on the computer disc for secondary offline analysis.

\section{OFFLINE DATA ANALYSIS}

The magnetic tape recordings were reviewed by medical experts trained to identify abnormal sounds and sounds that contained artefacts. The latter included audible noises due to tech- nical problems such as skin or hair friction noises, inadequate contact between the sensor and the skin, forced expiratory wheezes, speech, bowel sounds, or loud and irregular ambient background noises.

The digital breath sound data were analysed as follows. Two averaged spectra were generated (one for inspiration and one for expiration) for each of the three pick-up points (CR, BR, and $B L$ ) so that six spectra were analysed for each subject. The average spectra of the background noise recorded during a breath hold were subtracted from the corresponding breath sound spectra. An example of an average spectrum of a normal chest wall breath sound is shown in fig 3 as a plot of the $\log$ amplitude (in $\mathrm{dB}$ ) versus the log frequency (in $\mathrm{Hz}$ ). The offline data analysis was carried out by a computer program written in Microsoft Quick Basic. Two regression lines were fitted to each spectral curve in the log-log plane. One line was fitted to the data by least square linear

A

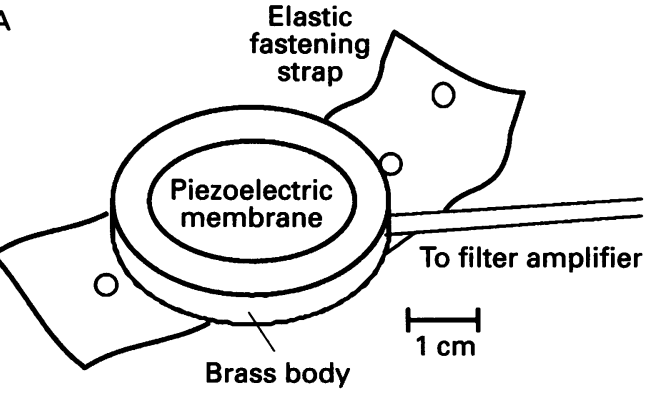

B

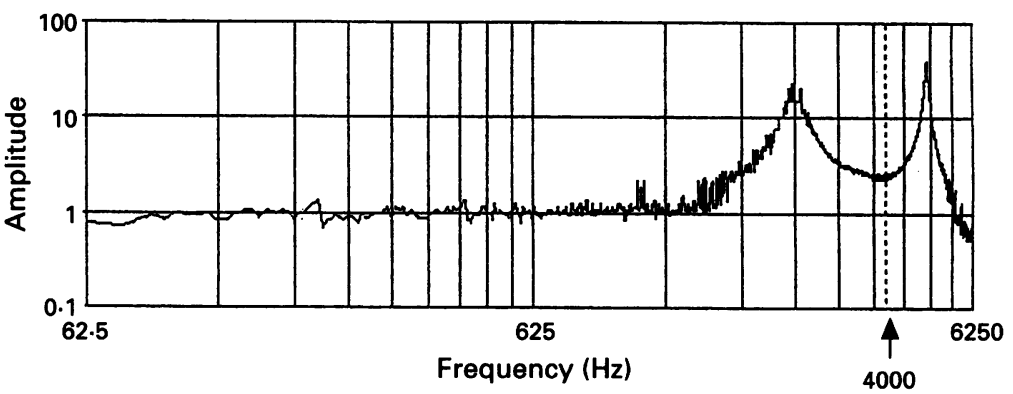

Figure 2 The piezoelectric sensor. (A) Sensor; (B) frequency response. 


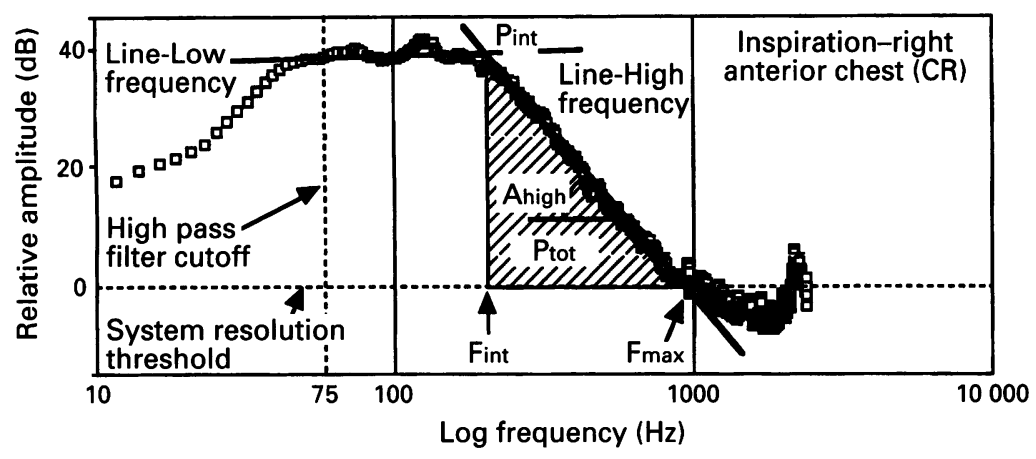

Figure 3 An example of a normal chest wall spectral curve. The average spectrum is from 10 inspiratory breathing sounds, showing the typical log-log pattern of the spectrum. Note the low and the high frequency regression lines and the indices used to characterise the spectrum. See text for explanation of parameter names. The vertical broken line at $75 \mathrm{~Hz}$ represents the cutoff frequency of the high pass filter. The horizontal broken line shows the resolution threshold of the system determined by the separation power of the (12 bit) analog-to-digital converter.

regression in the low frequency range from $75 \mathrm{~Hz}$ to $160 \cdot 2 \mathrm{~Hz}$ (spectral point no. 82). This point was selected based on a preliminary analysis of a smaller sample of the population. The second line was fitted to the high frequency data from $162 \cdot 1 \mathrm{~Hz}$ (spectral point no. 83) up to the maximal frequency (Fmax) in which the sound intensity is greater than the amplitude resolution of the experimental system determined by the resolution of the A/D converter. Fmax was detected by the program using an iterative running regression algorithm that searched for the end of the high frequency linear slope. The amplitude resolution of the $\mathrm{A} / \mathrm{D}$ - that is, the voltage increment between two successive digital values equal to $4.88 \mathrm{mV}$ in our system - was chosen as an objective baseline level that is independent of the signal's amplitude and can be easily transported from one experimental system to another. However, changing the dynamic range of the system or the resolution of the $A / D$ (for example, from 12 to 16 bit) may change (extend) Fmax by revealing faint sounds that cannot be detected by the present technology.

The minimum set of parameters needed to characterise the spectral curves of normal chest wall breath sounds consists of the slopes of the low and the high frequency regression lines (Alow and Ahigh, respectively), and the frequency and amplitude coordinates at the intersection of the two regression lines (Fint and Pint, respectively). In addition, we derived secondary parameters from the four primary ones including Fmax and the areas under the curve

Table 1 Mean (SD) basic parameters of normal test subjects

\begin{tabular}{lccccc}
\hline & $n$ & $\begin{array}{l}\text { Age } \\
\text { (years) }\end{array}$ & $\begin{array}{l}\text { Height } \\
(\mathrm{cm})\end{array}$ & $\begin{array}{l}\text { Weight } \\
(\mathrm{kg})\end{array}$ & $\begin{array}{c}\text { Pack } \\
\text { years }\end{array}$ \\
\hline Men & & & & & \\
$\quad$ Smokers & 150 & $46(11)$ & $172(7)$ & $80(14)$ & $25(17)$ \\
$\quad \begin{array}{l}\text { Non-smokers } \\
\text { All }\end{array}$ & 122 & $43(11)$ & $173(7)$ & $80(12)$ & - \\
Women & 272 & $44(11)$ & $173(7)$ & $80(13)$ & - \\
$\quad$ Smokers & 17 & $46(10)$ & $163(6)$ & $67(14)$ & $21(15)$ \\
$\quad \begin{array}{l}\text { All } \\
\quad\end{array}$ & 64 & $39(11)$ & $161(6)$ & $62(9)$ & - \\
Total & 81 & $40(11)$ & $162(6)$ & $63(10)$ & - \\
\hline & 353 & $44(11)$ & $170(8)$ & $75(15)$ & $25(17)$ \\
\hline
\end{tabular}

from $75 \mathrm{~Hz}$ to Fint, and from Fint to Fmax, which are measures of the total sound power (Ptot).

\section{QUALITY ASSURANCE AND SELECTION OF} SPECTRA

Since the goal of this study was to characterise the spectral pattern of normal breath sounds, it was important to assure that (a) all the sounds used for this study came from normal subjects, (b) that all the sounds were considered normal by auscultation, and (c) that all the sounds were free of artefacts and non-breath sound noises. To obtain this degree of selectivity using objective and quantitative criteria additional parameters were calculated and used, based on our previous experience. ${ }^{1}$ Normal breath sounds free of artefacts always tightly conformed to the spectral pattern shown in fig 3, whereas sounds that were abnormal or accompanied by non-breath sound noises did not fit this pattern. Parameters were therefore designed to determine the validity and quality of fit of the regression lines including the regression coefficient of the best fit line $(R)$ and the ratio coefficient (Rat). The latter was calculated using equation 1 from the high frequency portion of Ptot (see fig 3) measured as the area $S_{1}$ under the logarithmic spectral curve from Fint to Fmax, and the power under the corresponding best fit regression line which is the area $S_{2}$ of the triangle under the high frequency regression line. Rat is defined as:

$$
\text { Rat }=1-\left|1-S_{1} / S_{2}\right|
$$

Rat can have the value of one at the most, when $S_{1}$ and $S_{2}$ are identical. The combination of $R$ and Rat was previously found to provide adequate quality assurance of the linearity of the spectral curve. ${ }^{1}$ We designated as normal each spectrum of chest wall breath sound that had values of both $R$ and Rat of more than 0.75 and a combined value $(R+R a t)$ of more than $1 \cdot 7$. Curves that failed to meet these criteria usually displayed slope irregularities or had peaks of power. Using these criteria and logic we have included the data from 353 subjects whom we considered normal and, of the 2118 inspiratory and expiratory spectra obtained from these normal subjects, only 918 $(43 \%)$ satisfied the quality of fitness criteria outlined above and are included in the reported database.

\section{STATISTICAL ANALYSIS}

The data were analysed by two way analysis of variance (ANOVA) using a commercial statistical package (StatView SE +, Abacus Concept Inc, Berkeley, California, USA). Four independent parameters were used: sex, smoking (defining smokers as those subjects with more than five pack years cumulative cigarette smoking), sensor location (CR, BR, and BL), and respiratory phase (inspiration or expiration). A confidence level of $95 \%$ was considered statistically significant. All data are given as mean (SD). 

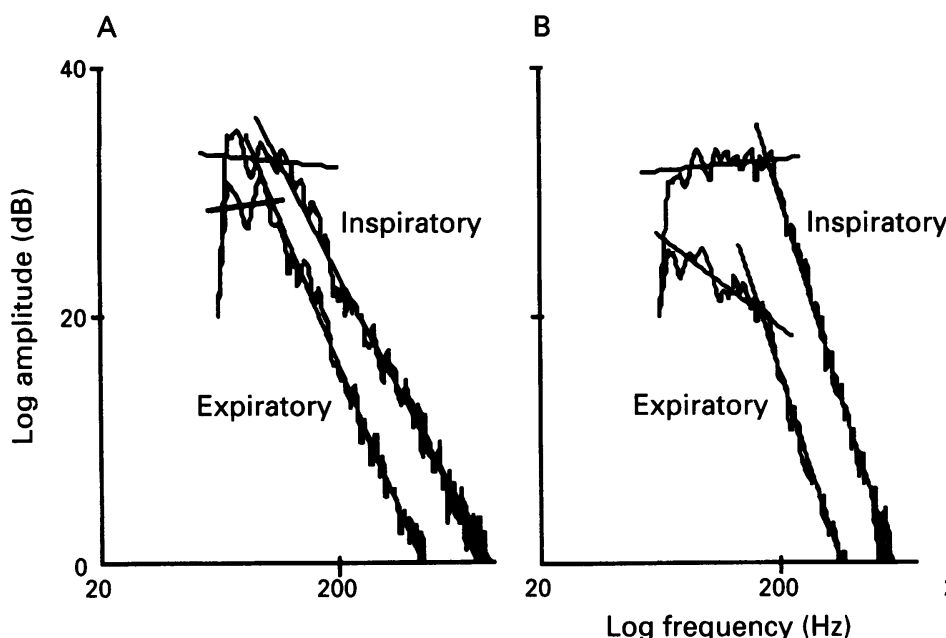

Figure 4 Example of a cumulative phonopneumograph data sheet of one subject from $(A)$ the right anterior chest, (B) the right posterior base, and $(C)$ the left posterior base. Note the variability of the low frequency regression lines and the stability of the high frequency lines.

\section{Results}

Lung sounds from 272 normal men of mean (SD) age 44 (11) years, height $173(7) \mathrm{cm}$, weight 80 (13) $\mathrm{kg}$ and 81 normal women of mean (SD) age 40 (11) years, height 162 (6) $\mathrm{cm}$, weight $63(10) \mathrm{kg}$ were recorded and analysed. One hundred and fifty $(55 \%)$ of the men and $17(21 \%)$ of the women were smokers (25 (17) and 21 (15) pack years, respectively (table 1)). The averaged spectra (see test procedure) were analysed offline and a typical panel of the final results from one subject is shown in fig 4. It is shown in a $\log$ amplitude versus $\log$ frequency format, enabling visual inspection of the parameters and properties listed below. The mean (SD) values of the parameters used to characterise the spectra are presented in tables 2 (men) and 3 (women) for all pick-up points during inspiration and expiration. A description of some prominent features of these data and their statistical significance (ANOVA) follows.

Ahigh - The overall range of mean slope values of the high frequency regression lines from Fint to Fmax was between $-12 \cdot 7 \mathrm{~dB} /$ oct and -20.6 $\mathrm{dB} /$ oct. The expiratory slopes at all pick-up locations were larger (steeper) than the inspiratory slopes $(-17 \cdot 6(4 \cdot 8)$ versus $-14 \cdot 1$ $(2 \cdot 3) \mathrm{dB} /$ oct, respectively, $\mathrm{p}<0.0001, \mathrm{~F}=$ $224 \cdot 5)$, with greater differences in $B R$ and $B L$ than in CR. The slopes at BR and BL were not different, but were significantly steeper than those at CR $(-16 \cdot 1(4 \cdot 4),-16 \cdot 3(3 \cdot 8)$, and $-13.8(2.3) \mathrm{dB} /$ oct, respectively, $\mathrm{p}<0.001$, $F=47 \cdot 6$ ). The differences between men and

Table 2 Mean (SD) phonopneumographic indices in healthy men

\begin{tabular}{|c|c|c|c|c|c|}
\hline & $\begin{array}{l}\text { Ahigh } \\
(d B / o c t)\end{array}$ & $\begin{array}{l}\text { Alow } \\
(d B / o c t)\end{array}$ & $\begin{array}{l}\text { Fint } \\
(\mathrm{Hz})\end{array}$ & Pint & $\begin{array}{l}F \max \\
(\mathrm{Hz})\end{array}$ \\
\hline $\begin{array}{l}\text { CR inspiration } \\
\text { Smokers } \\
\text { Non-smokers } \\
\text { All }\end{array}$ & $\begin{array}{l}-13.6(1.8) \\
-13.6(1.9) \\
-13.6(1.8)\end{array}$ & $\begin{array}{l}-8 \cdot 3(5 \cdot 8) \\
-4 \cdot 6(6 \cdot 4) \\
-6 \cdot 3(6 \cdot 4)\end{array}$ & $\begin{array}{l}153(38) \\
166(49) \\
160(45)\end{array}$ & $\begin{array}{l}55(26) \\
52(30) \\
53(28)\end{array}$ & $\begin{array}{l}805(209) \\
845(287) \\
822(247)\end{array}$ \\
\hline $\begin{array}{l}\text { CR expiration } \\
\text { Smokers } \\
\text { Non-smokers } \\
\text { All }\end{array}$ & $\begin{array}{l}-15.2(2.9) \\
-14.5(2.3) \\
-14.9(2.7)\end{array}$ & $\begin{array}{r}-13.5(17 \cdot 4) \\
-7.9(1.4) \\
-11.4(14 \cdot 0)\end{array}$ & $\begin{array}{l}187(43) \\
181(35) \\
184(41)\end{array}$ & $\begin{array}{l}26(25) \\
24(14) \\
25(22)\end{array}$ & $\begin{array}{l}593(124) \\
621(119) \\
604(123)\end{array}$ \\
\hline $\begin{array}{l}\text { BR inspiration } \\
\text { Smokers } \\
\text { Non-smokers } \\
\text { All }\end{array}$ & $\begin{array}{l}-14 \cdot 1(1 \cdot 8) \\
-14 \cdot 1(2 \cdot 0) \\
-14 \cdot 1(1 \cdot 9)\end{array}$ & $\begin{array}{l}-1.0(16.5) \\
-1.2(11.6) \\
-0.0(14.6)\end{array}$ & $\begin{array}{l}150(41) \\
162(35) \\
155(39)\end{array}$ & $\begin{array}{l}70(55) \\
65(68) \\
68(61)\end{array}$ & $\begin{array}{l}764(238) \\
754(212) \\
760(227)\end{array}$ \\
\hline $\begin{array}{l}\text { BR expiration } \\
\text { Smokers } \\
\text { Non-smokers } \\
\text { All }\end{array}$ & $\begin{array}{l}-19 \cdot 2(3.9) \\
-20 \cdot 4(6 \cdot 3) \\
-19 \cdot 7(5 \cdot 1)\end{array}$ & $\begin{array}{l}-9.9(3.8) \\
-1.7(7.8) \\
-6.5(7.1)\end{array}$ & $\begin{array}{l}149(18) \\
150(13) \\
150(16)\end{array}$ & $\begin{array}{l}44(56) \\
16(6) \\
32(45)\end{array}$ & $\begin{array}{l}429(114) \\
405(107) \\
419(112)\end{array}$ \\
\hline $\begin{array}{l}\text { BL inspiration } \\
\text { Smokers } \\
\text { Non-smokers } \\
\text { All }\end{array}$ & $\begin{array}{l}-15 \cdot 0(2 \cdot 6) \\
-15 \cdot 4(2 \cdot 7) \\
-15 \cdot 2(2 \cdot 6)\end{array}$ & $\begin{array}{l}-5 \cdot 5(7 \cdot 2) \\
-4 \cdot 5(6 \cdot 7) \\
-5 \cdot 0(7 \cdot 0)\end{array}$ & $\begin{array}{l}156(18) \\
165(14) \\
160(17)\end{array}$ & $\begin{array}{l}58(48) \\
47(27) \\
53(41)\end{array}$ & $\begin{array}{l}758(210) \\
710(187) \\
736(201)\end{array}$ \\
\hline $\begin{array}{l}\text { BL expiration } \\
\text { Smokers } \\
\text { Non-smokers } \\
\text { All }\end{array}$ & $\begin{array}{l}-18.6(4.5) \\
-19.1(4.2) \\
-18.8(4.4)\end{array}$ & $\begin{array}{l}-6.5(5.4) \\
-7 \cdot 2(7.0) \\
-6.7(5.9)\end{array}$ & $\begin{array}{l}158(34) \\
150(20) \\
155(30)\end{array}$ & $\begin{array}{l}28(19) \\
14(3) \\
23(17)\end{array}$ & $\begin{array}{l}435(100) \\
413(12) \\
426(87)\end{array}$ \\
\hline
\end{tabular}

$\mathrm{CR}=$ right anterior chest; $\mathrm{BR}=$ base of right lung; $\mathrm{BL}=$ base of left lung; Ahigh =slope of high frequency regression line; Alow = slope of low frequency regression line; Fint $=$ frequency at intersection of low and high frequency regression lines;
Pint = power at intersection of low and high frequency regression lines; Fmax = maximal frequency of sounds; dB/oct $=$ decibel Pint = power at intersection of low and high frequency regression lines; Fmax $=$ maximal frequency of sounds; dB/oct $=\mathrm{d}$ per octave, slope in log-log presentation designates number of decibel changes in amplitude when frequency is doubled.
per 
Table 3 Mean (SD) phonopneumograph indices in healthy women

\begin{tabular}{|c|c|c|c|c|c|}
\hline & $\begin{array}{l}\text { Ahigh } \\
\text { (dB/oct) }\end{array}$ & $\begin{array}{l}\text { Alow } \\
\text { (dB/oct) }\end{array}$ & $\begin{array}{l}\text { Fint } \\
(\mathrm{Hz})\end{array}$ & Pint & $\begin{array}{l}F \max \\
(\mathrm{Hz})\end{array}$ \\
\hline $\begin{array}{l}\text { CR inspiration } \\
\text { Smokers } \\
\text { Non-smokers } \\
\text { All }\end{array}$ & $\begin{array}{l}-14.4(1 \cdot 7) \\
-12 \cdot 7(1 \cdot 7) \\
-12.9(1 \cdot 7)\end{array}$ & $\begin{array}{r}-\overline{8}(5 \cdot 6) \\
-5 \cdot 8(5 \cdot 6)\end{array}$ & $\begin{array}{r}- \\
18 \overline{2}(52) \\
182(52)\end{array}$ & $\begin{array}{l}-\overline{45}(21) \\
45(21)\end{array}$ & $\begin{array}{r}898(342) \\
1015(247) \\
999(265)\end{array}$ \\
\hline $\begin{array}{l}\text { CR expiration } \\
\text { Smokers } \\
\text { Non-smokers } \\
\text { All }\end{array}$ & $\begin{array}{l}-12.9(3.5) \\
-13.4(1.7) \\
-13.4(1.9)\end{array}$ & $\begin{array}{r}-\overline{7}(7 \cdot 7) \\
-4 \cdot 7(7 \cdot 7)\end{array}$ & $\begin{array}{r}- \\
178(52) \\
173(52)\end{array}$ & $\begin{array}{l}- \\
28(14) \\
28(14)\end{array}$ & $\begin{array}{l}-\overline{6}(145) \\
794(142)\end{array}$ \\
\hline $\begin{array}{l}\text { BR inspiration } \\
\text { Smokers } \\
\text { Non-smokers } \\
\text { All }\end{array}$ & $\begin{array}{l}-14.2(2 \cdot 5) \\
-13.7(1 \cdot 8) \\
-13.8(2 \cdot 0)\end{array}$ & $\begin{array}{l}-6 \cdot 1(0 \cdot 7) \\
-5 \cdot 0(6 \cdot 4) \\
-5 \cdot 4(5 \cdot 2)\end{array}$ & $\begin{array}{l}175(14) \\
149(5) \\
157(15)\end{array}$ & $\begin{array}{l}50(8) \\
82(35) \\
71(32)\end{array}$ & $\begin{array}{l}799(304) \\
855(209) \\
843(133)\end{array}$ \\
\hline $\begin{array}{l}\text { BR expirations } \\
\text { Smokers } \\
\text { Non-smokers } \\
\text { All }\end{array}$ & $\begin{array}{l}-19 \cdot 6(2 \cdot 3) \\
-20 \cdot 6(4 \cdot 7) \\
-20 \cdot 3(4 \cdot 2)\end{array}$ & $\begin{array}{l}-8 \cdot 8(0.5) \\
-3.0(8 \cdot 4) \\
-5 \cdot 3(7 \cdot 1)\end{array}$ & $\begin{array}{l}140(23) \\
153(18) \\
147(21)\end{array}$ & $\begin{array}{l}33(9) \\
28(16) \\
30(14)\end{array}$ & $\begin{array}{l}438(51) \\
413(61) \\
420(60)\end{array}$ \\
\hline $\begin{array}{l}\text { BL inspiration } \\
\text { Smokers } \\
\text { Non-smokers } \\
\text { All }\end{array}$ & $\begin{array}{l}-14.5(3 \cdot 2) \\
-14.7(2 \cdot 4) \\
-14.7(2 \cdot 6)\end{array}$ & $\begin{array}{l}-5 \cdot 8 \\
-7 \cdot 0(1 \cdot 4) \\
-6 \cdot 8(1 \cdot 4)\end{array}$ & $\begin{array}{l}174 \\
154(15) \\
157(16)\end{array}$ & $\begin{array}{l}24 \\
82(23) \\
74(29)\end{array}$ & $\begin{array}{l}800(253) \\
902(242) \\
885(247)\end{array}$ \\
\hline $\begin{array}{l}\text { BL expiration } \\
\text { Smokers } \\
\text { Non-smokers } \\
\text { All }\end{array}$ & $\begin{array}{l}-18 \cdot 7(3 \cdot 7) \\
-17 \cdot 4(3 \cdot 7) \\
-17 \cdot 7(3 \cdot 8)\end{array}$ & $\begin{array}{l}- \\
-8 \cdot 0(1 \cdot 0) \\
-8 \cdot 0(1 \cdot 0)\end{array}$ & $\begin{array}{r}- \\
140(18) \\
140(18)\end{array}$ & $\begin{array}{l}24(9) \\
24(9)\end{array}$ & $\begin{array}{l}445(59) \\
443(63) \\
444(62)\end{array}$ \\
\hline
\end{tabular}

For definition of abbreviations see footnote to table 2 .

women and between smokers and non-smokers were not statistically significant.

The overall range of mean regression coefficient (R) values for the high frequency line was $0 \cdot 89-0 \cdot 95$. The inspiratory lines had somewhat higher values of $R$ in $B R$ and BL $(p<0.05)$. The other quality parameter (Rat) was between 0.88 and 0.98 , with no significant differences between respiratory phase, sex, or smoking history. These values indicate a reasonably good fit between the actual data and the calculated regression line.

Alow - The mean slope of the line fitted to the lower frequencies between $75 \mathrm{~Hz}$ and Fint was approximately $-5 \mathrm{~dB} /$ oct but varied substantially and inconsistently among pick-up points, subjects, and breathing phases. The mean low frequency regression coefficient was $0 \cdot 81$, significantly lower than that of the high frequency line, and was only seldom higher than $0 \cdot 84$.

Fint, Pint - The mean frequency at intersection between the high and low frequency regression lines was $160 \mathrm{~Hz}$ (range among pick-up locations: $140-184 \mathrm{~Hz})$. The variance was relatively small (tables 2 and 3 ) with no consistent or significant differences between respiratory phase, sex, or smoking status. Pick-up location was found to affect Fint, with statistically significant higher values at $C R$ than at $B R$ and BL $(p<0 \cdot 01)$. The amplitude at the point of intersection, Pint, was $215 \%$ higher in the inspiratory than in the expiratory spectra $(p<0.001, F=79.9)$. The expiratory amplitude values in male smokers at $\mathrm{BR}$ and $\mathrm{BL}$ locations were higher than in the non-smokers (see below). Differences among the other subgroups were not significant.

Fmax - The maximal frequency was always higher in inspiration than in expiration (inspiratory $\mathrm{Fmax}=803(243) \mathrm{Hz}$, expiratory $F \max =496 \quad(157) \mathrm{Hz}, \mathrm{p}<0.0001, \quad F=439)$.
These differences were somewhat greater at $B R$ and BL than at CR $(p<0.05)$ in both sexes. The inspiratory Fmax values in women were $12-19 \%$ higher than in men at all the points (767 (246) versus $667(246) \mathrm{Hz}, \mathrm{p}<0 \cdot 001, \mathrm{~F}=$ $25 \cdot 3)$. The expiratory Fmax values at $C R$ were $32 \%$ higher in women, but were similar among the sexes at both BR and BL. The values of Fmax were highest at $\mathrm{CR}$ and less so at $\mathrm{BR}$ and BL which were similar to each other (789 (251) versus $649(261) \mathrm{Hz}$ and $639(245) \mathrm{Hz}$, respectively, $\mathrm{p}<0 \cdot 0001, \mathrm{~F}=33 \cdot 4$ ).

One hundred and twenty two (45\%) men and $64(79 \%)$ women were non-smokers. The results in the smokers were similar to the results in the non-smokers in nearly all parameters. Smoking habits affected the expiratory Pint at $B L$ and $B R$ in men where acoustic amplitude was 2-3 times higher in the smokers (table 2) ( $\mathrm{p}<0.05$ by paired Student's $t$ test).

\section{Discussion}

The present study is an elaboration and extension of an earlier study ${ }^{1}$ using a similar approach and techniques but with improved electronics and computers. A much larger population has been tested, leading to a more detailed description of the normal chest wall breath sound and to a better statistical significance. This database is intended to provide a set of parameters for use as reference values for normal chest wall breath sounds.

Terminology in this field is confusing. Normal chest wall breath sounds have been called "vesicular lung sounds" in physical examination texts $^{10}$ even though most investigators agree that these sounds do not originate from air flow in the alveoli (vesicles). We propose the term "normal chest wall breath sounds" as a descriptive, non-mechanistic term for sounds picked up over the chest wall of normal sub- 


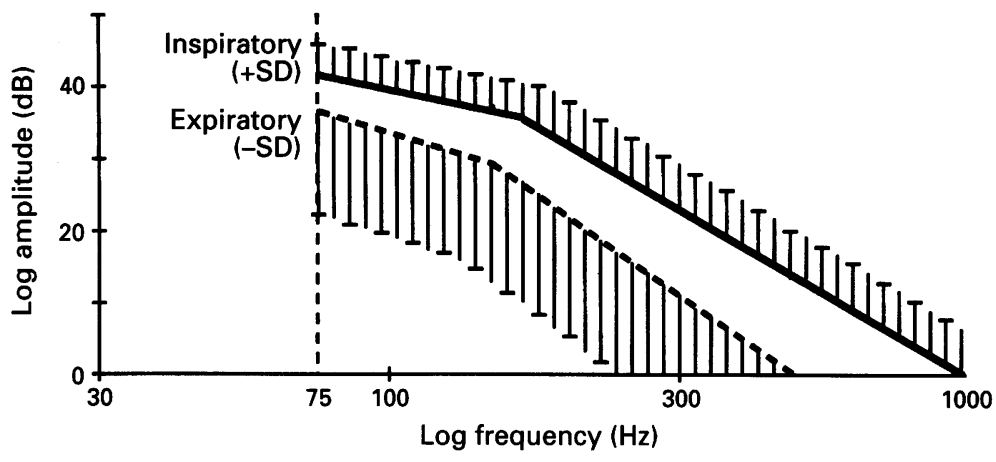

Figure 5 Reconstruction of spectral patterns of inspiratory (heavy line) and expiratory (dashed line) chest wall breath sounds. See text and equation (2) for explanation.

jects. Likewise, we propose the term "normal tracheal breath sounds" for sounds picked up over the anterior neck of normal subjects.

Strict criteria were applied to assure that only normal breath sounds were included in this database so only spectra from the 353 subjects who were normal based on their spirometric data, respiratory health questionnaire, and auscultation were included. Of the 2118 inspiratory and expiratory spectra from these normal subjects, $56 \cdot 7 \%$ were rejected on the basis of objective criteria for the goodness of fit of the spectral pattern to the two regression lines. We have previously observed ${ }^{1}$ that spectra that fulfil these criteria were always associated with normal breath sounds. This was further verified in the present study by recording and then listening to all sounds by experienced observers. All 918 spectra that were included were deemed to sound normal. While the criteria for rejection were absolute and common for all spectra, there were several underlying causes. These included environmental and body noises, poor sensor contact, acoustic or electrical artefacts, and low signal-to-noise (background noise) ratio. ${ }^{15}$ It is possible that some normal spectra were rejected due to the high values of $\mathrm{R}$ and RAT used. However, relaxing these criteria did not result in any significant changes in the values of the parameters presented in tables 2 and 3.

The spectral pattern of normal chest wall breath sounds in the log-log plane is simple: a relatively flat segment extending to approximately $160 \mathrm{~Hz}$ followed by a linear decline of $\log$ amplitude with increasing $\log$ frequency extending to meet the frequency axis at a point defined as the maximal frequency (Fmax). The latter part of the spectrum was identified in $1981^{1}$ but the low frequency portion of the spectrum was overlooked at that time. Fitting two least square linear regression lines to the spectra provides a complete and reliable description of the signal. Only four parameters are needed to characterise each spectrum: the slopes of the two lines (Alow and Ahigh) and the frequency and amplitude coordinates of the intersection between the lines (Fint and Pint, respectively). These four parameters can serve as the basis for automatic identification of normal and abnormal chest wall breath sounds and for efficient signal compression. It is also possible to reconstruct an "idealised" spectrum and to generate artificial breath sounds by use of a modulated inverse Fourier transform technique. It should be noted that, since the deflection of the spectral curve is insidious, its identification is based on extending (extrapolating) the two regression lines to their point of intersect. Thus, the accuracy of the deflection coordinates (Fint; Pint) is directly related to the goodness of fit of the two linear regression lines. The cumulative data from tables 2 and 3 were used to reconstruct spectra of normal inspiratory and expiratory chest wall sounds (fig 5). To do so we used the following two equations, one for the low frequency and one for the high frequency range:

$$
\begin{aligned}
\log \mathrm{P}= & \frac{\text { Alow }}{20 \log 2} \cdot \log \mathrm{F}+\log \frac{\text { Pint }}{\text { Fint }\left(\frac{\text { Alow }}{20 \log 2}\right)} \\
\text { for } 75 \mathrm{~Hz}<\mathrm{F}<\text { Fint } & \\
\log \mathrm{P}= & \frac{\text { Ahigh }}{20 \log 2} \cdot \log \mathrm{F}+\log \frac{\text { Pint }}{\text { Fint }\left(\frac{\text { Ahigh }}{20 \log 2}\right)}
\end{aligned}
$$$$
\text { for Fint }<\mathrm{F}<\mathrm{Fmax}
$$

These equations are of the form $\mathrm{Y}=\mathrm{aX}+\mathrm{b}$, where $\mathrm{Y}$ and $\mathrm{X}$ correspond to $\log \mathrm{P}$ and $\log \mathrm{F}$ respectively, and $a$ and $b$ are the coefficients. (The term " $20 \log 2$ " is from the db/oct units of the slope).

The reconstructed spectra of fig 5 are based on the overall means and variances of the values found in the present study, and demonstrate several features of normal breath sounds. The general pattern of the inspiratory and expiratory curves is the same, but the total energy in the expiratory sounds is less than in the inspiratory sounds and the high frequency slope is steeper. Consequently, the expiratory Fmax is substantially lower than the inspiratory value. This shift to lower frequencies, where human auditory sensitivity is reduced, contributes to the perceived reduced sound intensity of expiratory sounds during stethoscopic auscultation. The mechanisms that determine sound intensity in inspiration versus expiration with essentially the same flow rate are as yet unknown. Our studies, as well as those of others, indicate that the distribution of sound generation within the airways may be different for the two respiratory phases and is related to the distribution of bronchial turbulence and flow instabilities. However, the site of generation of normal breath sounds and their modulating factors are yet to be formulated in modern engineering terms. The significantly greater steepness of the expiratory high frequency slope (Ahigh) is a new observation that must be considered whenever construction of an acoustic model of the respiratory system is attempted.

The variance of spectral curves is also shown in fig 5 with a greater value in expiration. In a large population, and with lumping data from several pick-up locations, an overlap between the ranges of normal inspiratory and expiratory spectral curves is seen. A better separation 


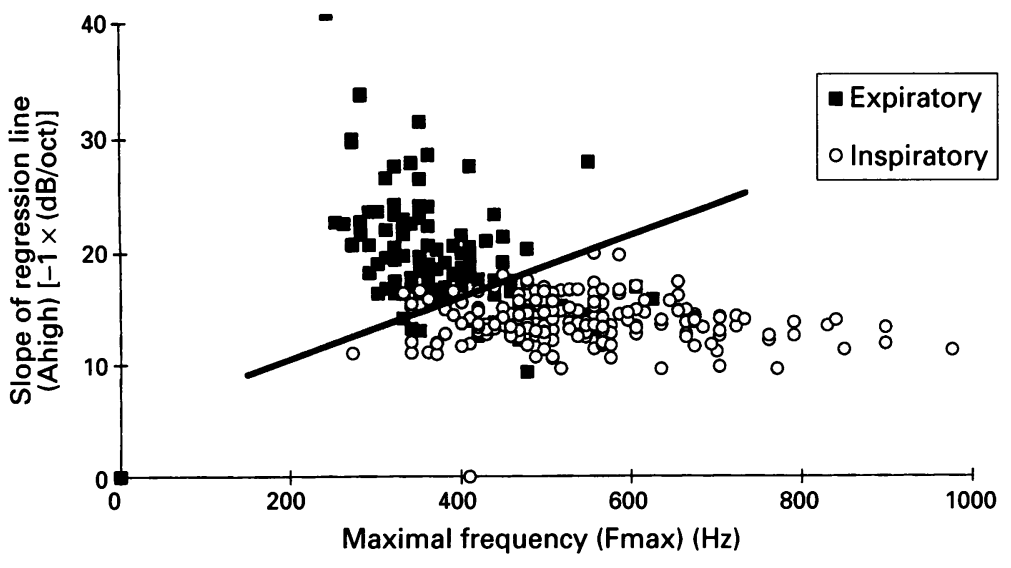

Figure 6 Example of the use of spectral indices to separate inspiratory and expiratory spectra. Data are inspiratory and expiratory average spectra of breath sounds from the right posterior base of normal men. The slope of the high frequency regression line (Ahigh) and the maximal frequency (Fmax) provide the best separation power.

between inspiratory and expiratory spectral parameters can be achieved using simplified cluster analysis with independent parameters. After trial and error we found that the best two parameters that were mutually independent and provide the best discrimination between spectral patterns were Ahigh and Fmax. An example is shown in fig 6 where the values of the two parameters for inspiratory and expiratory spectra from BR in the men are plotted in an orthogonal coordinate system. The diagonal line separates the two clusters so that a point that is above and to the left of the line is likely to be expiratory and a point under and to the right of the line is inspiratory.

Our data demonstrate a gender difference in the inspiratory Fmax values at all the pick-up locations, but in the expiratory Fmax at CR only. The women had Fmax values that were $12-19 \%$ higher than in the men. These differences were statistically significant $(p<0.01)$. They are partially due to slightly shallower slopes of the high frequency regression line and partially due to a higher Pint. Neither of these two differences were statistically significant, but their combined effect on Fmax reached significance. This observation indicates that, on average, breath sounds in normal women contain higher frequency components than in men. We found no reference to this observation in physical examination texts, but it does correlate with our own personal clinical auscultatory impression. The mechanism of this finding is not clear. It may reflect differences in sound generation within the bronchi, differences in sound transmission and attenuation in the lung parenchyma, differences in impedance matching between the lung and the chest wall, or altered chest wall mass and physical properties. Investigation of the mechanisms of this and other details of normal breath sounds is important if these signals are used for screening and diagnosis of lung abnormalities.

Expiratory breath sounds at the posterior lung bases had a higher intensity in smokers than in non-smokers. This difference was unexpected, particularly since a cutoff point of five pack years represents minimal cigarette use. Changing the cutoff to 20 pack years did not affect the results. In a 1974 letter to the editor Laird et $a l^{11}$ described phonopneumographic changes due to cigarette smoking in hamsters and in three women, but the nature of the changes is unclear. The mechanism underlying this observation in smokers who have no clinical evidence of lung abnormalities is not known. Narrowing and/or irregularities in the airways is likely to affect the distribution and extent of turbulence and flow separation within the bronchi. The clinical and epidemiological significance of our findings should be further validated and evaluated.

Deviations from the normal pattern are easily detected and documented when average spectra are examined. These deviations include peaks of amplitude superimposed on the normal pattern, extension of spectral amplitude beyond the range of normal Fmax values, deformation of the high frequency linear segment of the spectrum, usually into a "staircase" pattern, or appearance of a "tracheal" pattern (broad band noise pattern). Examples of some of these abnormalities have been published elsewhere. ${ }^{2}$ The detailed data in tables 2 and 3 define strict boundaries of normal values and may be used as reference databases for comparison of measurements done in clinical settings as well as during screening for lung diseases.

The representation of the spectra, using a set of only four parameters, is advantageous for automated computerised analysis of the signals. Other methods that have been used to characterise the spectra of normal breath sounds include the use of quartiles ${ }^{12}$ which divide the spectrum into equal area sections and the calculation of spectra from parameters of an autoregressive analysis of the signal. ${ }^{1314}$ The present study was not designed as a comparative evaluation of the advantages and disadvantages of the various methods for characterisation of breath sound spectra. Spectral analysis of breath sounds differentiates normal subjects from patients with pulmonary abnormalities. While the use of appropriate methodology for objective and quantitative recording of these non-invasive signals is essential, the availability of a reference database is also needed to facilitate the use of respiratory sounds for screening in epidemiological and occupational settings.

\section{Appendix: algorithm for calculation of spirometric score}

This algorithm is designed to distinguish between subjects with normal spirometric values and those with abnormal volumes, independent of the underlying disease or severity ("diagnosis of the healthy"). ${ }^{2}$ The subject's initial score is 0 (zero) and a value indicated below is added to his/her score whenever a value under the specified thresholds is found in the results of pulmonary function tests. The thresholds are given as percentage predicted values based on the European standards. We considered subjects with a scores of $0-2$ as having normal spirometric values. 
$\mathrm{FEV}_{1 \cdot 0}<85 \%$ of predicted $=+1$

$\mathrm{FEV}_{1 \cdot 0}<80 \%$ of predicted $=+4$

FVC $<85 \%$ of predicted $=+1$

FVC $<80 \%$ of predicted $=+4$

$\mathrm{FEV}_{1.0} / \mathrm{FVC}<90 \%$ of predicted $=+3 *$

$\mathrm{FEF}_{25-75 \%}<65 \%$ of predicted $=+1$

$\mathrm{FEF}_{25-75 \%}<50 \%$ of predicted $=+4$

$\mathrm{FEV}_{1 \cdot 0}=$ forced expiratory volume in one second; FVC = forced vital capacity; $\mathrm{FEF}_{25-75 \%}=$ forced expiratory flow in the $25-75 \%$ portion of the exhaled vital capacity.

* If FVC is greater than $105 \%$ of predicted then add three points only if $\mathrm{FEV}_{1 \cdot 0} / \mathrm{FVC}<85 \%$ of predicted.

This study was supported by the Committee for Research and Prevention in Occupational Safety and Health, Ministry of Labor and Social Affairs, Israel.

1 Gavriely N, Palti Y, Alroy G. Spectral characteristics of normal breath sounds. Appl Physiol Respirat Environ Exerc Physiol 1981;50:307-14.

2 Gavriely N, Nissan M, Cugell DW, Rubin AE. Respiratory health screening using pulmonary function tests and lung sound analysis. Eur Respir f 1994;7:35-42.
3 Thorpe CW, Fright WR, Toop LJ, Dawson KP. A microcomputer-based interactive cough sound analysis system. Comp Methods Prog Biomed 1991;36:33-43.

4 Murphy RLH, Holford SK. Lung sounds. Basics of RED 1980;8:1-6.

5 Murphy RLH, Holford SK, Knowler WC. Visual lungsound characterization by time-expanded wave-form analysis. $N$ Engl $₹$ Med 1977;296:968-71.

6 Nissan M, Rubin AE, Cugell DW, Gavriely N. A Hebrew respiratory health questionnaire for occupational screening (Hebrew). Harefuah 1990:119:132-4.

7 Nissan M, Gavriely N. Lung sound recording, analysis and real time presentation using a micro-computer. In: Held $\mathrm{KD}$, Brebbia CA, Ciskowski RD, eds. Computers in biomedicine. Southampton, UK: Computational Mechanics Publications, 1991:87-95.

8 Nissan M, Gavriely N. A micro-computer based lung sound analysis. Comp Methods Prog Biomed 1993;40:7-13.

9 Gavriely N, Nissan M, Rubin AE, Cugell DW. Breath sound analysis in pulmonary screening at work. 17 th International analysis in pulmonary screening at work. 17th Internationd

10 MacLeod J. Clinical examination. 4th edn. Churchill Livingstone, 1976

11 Laird CW, Homburger F, Ishikawa S. Breath sound changes after cigarette smoking. Lancet 1974;i:808.

12 Anderson K, Aitken S, Carter R, Macleod JES, Moran F. Variation of breath sound and airway caliber induced by histamine challenge. Am Rev Respir Dis 1990;141: 1147-50.

13 Gavriely N, Herzberg M. Parametric representation of normal breath sounds. F Appl Physiol 1992;73:1776-84.

14 Cohen A, Landsberg D. Analysis and automatic classification of breath sounds. IEEE Trans Biomed Eng 1984; BME-31:585-90.

15 Gavriely N, Cugell D W. Breath sounds methodology. Boca Raton, Florida: CRC Press, 1995. 